\title{
Methane-Air Equivalence Ratio Effect on Premixed Turbulent Low Swirl Stabilized Flame
}

\author{
S. OuAli ${ }^{a, *}$, A.H. BenteBbiche ${ }^{b}$ And T. BelmraBeT ${ }^{c}$ \\ ${ }^{a}$ Departement d'Énergétique, Faculté des Sciences de l'Ingénieur UMBB, Boumerdes, 35000, Algérie \\ ${ }^{b}$ Laboratoire de Systèmes d'Énergie, Faculté de Mécanique, USTHB, Alger, 16111, Algérie \\ ${ }^{c}$ Ecole Militaire Polytechniques, EMP, Alger, 16000, Algérie
}

(Received January 29, 2014; revised version May 9, 2014; in final form May 27, 2014)

\begin{abstract}
This work presents a numerical simulation of premixed methane-air low swirl stabilized flame, the geometry describes a low swirl burner kind. Reynolds average Navier-Stokes standard $\kappa-\varepsilon$ model for turbulence coupling to partially premixed model for combustion were used with varying methane equivalence ratio from 0.6 to 1.4 . Parameters governing flame structure are investigated; velocity, temperature, $\mathrm{CH}_{4}$ distribution and thermal nitric oxide apparitions fields, results are compared and validated with experimental and large eddy simulation works cited in references, they offer good similarities for all flame parameters studied. Actual study works to find equilibrium between the maximum of generated temperature and the minimum of thermal NO pollutant emissions for low swirl burners without neglecting the flame stabilization which must be maintained.
\end{abstract}

DOI: 10.12693 /APhysPolA.126.717

PACS: 47.70.pq, 47.27.E, 47.32.Ef

\section{Introduction}

Swirling lean premixed flames are frequently used in modern gas turbine combustors since they offer a possibility of controlled flame temperature and thus favorable thermal $\mathrm{NO}_{x}$ emissions and avoid intrusive methods disturbing flow field [1]. High swirl burner (HSB) where the van swirler took almost entire diameter of the nozzle burner generated a large zone of recirculation (vortex) where he traps hot products of combustion that continuously ignites fresh mixtures [2], thus increases zones of high temperature which includes most important emissions of thermal NO while the flame was stabilized near to the nozzle burner walls which generates a premature break-in of the burner structure [3]. Researches are directed to develop a burner with the same operating conditions (flame stabilization technique) low swirl burner (LSB) while reducing swirl factor by changing several parameters; reduce diameter of the annular space containing swirl vanes and by modifying global burner geometry.

Many researches were engaged in LSB studies to ameliorate prediction of pollutants apparitions, create a data base validation for different models of combustion coupled to turbulence and develop a swirled burner generating a flame without recirculation zone implying low thermal NO creations.

The discovery of low swirl stabilization flame method by Cheng [4] in 1991 to study the dynamic and chaotic interactions between turbulent flow and premixed combustion gave to scientists a considerable projection in this research axis; an experimental of the turbulent burning velocity and the structure of premixed flames on a LSB

*corresponding author; e-mail: sofianeouali2@hotmail.fr using particle image velocimetry is developed in Ref. [5]. The behavior of a premixed turbulent methane flame in three dimensions using numerical simulation at low Mach number is studied in Ref. [6]. Flow fields and burners emissions at high swirl number for HSB and LSB are compared in Ref. [7]. A numerical simulation of swirl effect on combustion dynamics in lean premixed swirl stabilized combustion has been undertaken in Ref. [8]. Multipoint measurements of flame emission spectra using two Cassegrain mirrors and two spectrometers, they used results to obtain the correlation of the intensity ratio to the equivalence ratio for laminar flames is examined in Ref. [9]. A numerical simulation of Lewis number effect of lean premixed turbulent flames is proposed in Ref. [10]. The turbulent flux in turbulent premixed swirl flames is studied experimentally in Ref. [11]. Numerical large eddy simulation (LES) of a fuel in lean premixed turbulent swirling flame is executed in Ref. [12]. Numerical LES of LSB [4] burner for turbulent premixed methane-air flames and published a study where they changed the calculation source term in the $G$-equation combustion model and compared it with the $C$-equation model and his own experiences is proposed in Ref. [13]. LSB comportment with adding hydrogen is studied in Ref. [14]. Experimental study about high speed measurements using PIV and $\mathrm{OH}$ planar laser induced fluorescence, with analyze of flame models for LSB burner kind, has been developed in Ref. [15].

The goal of actual study is flame behavior according to $\mathrm{CH}_{4}$ equivalence ratio increasing; flow field, thermal field, $\mathrm{CH}_{4}$ distribution and thermal $\mathrm{NO}$ apparition are analyzed using commercial code Fluent 14 with RANS Standard $\kappa-\varepsilon$ model to treat turbulence coupling to partially premixed model to treat combustion. Models are applied to a three-dimensional geometry, they gave suitable results and were able to describe a detailed flow field. 
Vortexes were nonexistent for all studied equivalence ratio of $\mathrm{CH}_{4}$, while thermal field changed with this increase accordingly.

\section{Modeling and numerical simulation}

Conservation equations governing reactive flows resolved by the numerical code Ansys Fluent 14 [16] actual investigation are: mass, momentum, species and energy conservation equations using several models described below with finite volume methods.

To treat turbulence, RANS Standard $\kappa-\varepsilon$ turbulence model based on two equations was employed (proposed by [17]). It can estimate the length of turbulence and the time scale independently by solving two transport equations.

Partially premixed combustion model was selected to treat combustion, it is a form of premixed flames model with non-uniform fuel-oxidizer mixtures [16], exploiting $c$-equation model to calculate the progress variable $c$ with Zimont model to calculate turbulent flame speed ([18-20]) and the chemical equilibrium model based on a PDF [21] for turbulence chemistry coupling.

Chemical equilibrium model used in Fluent [16] considers 19 chemical species in chemical equilibrium state $\left(\mathrm{CH}_{4}, \mathrm{~N}_{2}, \mathrm{O}_{2}, \mathrm{O}, \mathrm{O}_{3}, \mathrm{CO}, \mathrm{CO}_{2}, \mathrm{H}, \mathrm{H}_{2}, \mathrm{H}_{2} \mathrm{O}, \mathrm{HO}_{2}, \mathrm{OH}\right.$, $\mathrm{HONO}, \mathrm{H}_{2} \mathrm{O}_{2}$, HOCO, CHO, HCO, $\mathrm{HCOOH}$, and $\mathrm{C}_{2} \mathrm{H}_{6}$ ) using an algorithm of Gibbs energy minimization method where each species is treated independently without specifying a set of reactions [16].

NO pollutants creations are analyzed by the thermal NO model by adding equation to the conservation equations system of chemical species [22-24].

\section{Validation and geometry}

Obtained results are validated with experiments and LES numerical simulation works of [13].

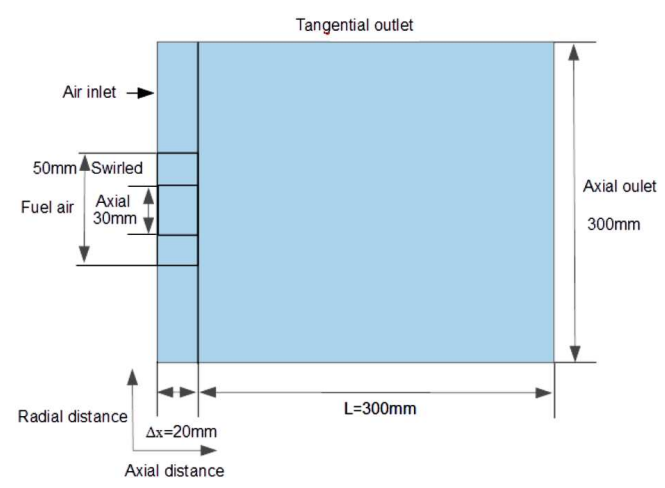

Fig. 1. Computational domain configuration.

The volume of control is shown in Fig. 1. The geometry is open to atmospheric pressure. In this configuration, the flame is stabilized by a low swirl number $(S=0.5)$ that consists of a nozzle $D=50 \mathrm{~mm}$ diameter divided into two parts, axial perforated plate of $30 \mathrm{~mm}$ where the flow is purely axial and an annular space which forms the valve swirler of $20 \mathrm{~mm}$ with concurrent flow of air surrounding the nozzle.

\subsection{Operating and boundary conditions}

The flow is considered permanent and threedimensional, used parameters in the numerical simulation using Ansys Fluent 14 code are shown in Table I with the pressure-based solver [25] which is an algorithm that belongs to a general class of methods called projection method and SIMPLEC scheme proposed by [26] with second order solver algorithms pressure based are available as isolated algorithm.

TABLE I

Operating conditions.

\begin{tabular}{l|c}
\hline \hline operating pressure & 1 atm \\
solver & pressure based \\
equivalence ratio $\Phi$ of $\mathrm{CH}_{4}$ & $0.6,0.8,1,1.2,1.4$ \\
swirl number $S$ & $\approx 0.5$ \\
inlet temperature $T$ & $300 \mathrm{~K}$ \\
mean velocity inlet $V_{0}$ & $5 \mathrm{~m} / \mathrm{s}$ \\
Reynolds number $R e$ & 11400 \\
turbulent Schmidt number & 0.5 \\
PDF Schmidt number & 0.85 \\
Prandtl number $P r$ & 0.85
\end{tabular}

TABLE II

Boundary conditions (a)-(c). $\quad V_{\text {ax }}$ - axial component velocity, $V_{\text {rad }}$ - radial component velocity, $V_{s}$ - tangential component velocity, $I$ - turbulent intensity, $D_{\mathrm{h}}$ - hydraulic diameter.

\begin{tabular}{c|c|c|c|c|c|c|c}
\hline \hline case & $V_{\mathrm{ax}}$ & $V_{\mathrm{rad}}$ & $V_{s}$ & $I$ & $D_{\mathrm{h}}$ & $\mathrm{O}_{2}$ & $\mathrm{~N}_{2}$ \\
\cline { 2 - 3 } \cline { 6 - 8 } & \multicolumn{3}{|c|}{$[\mathrm{m} / \mathrm{s}]$} & & {$[\%]$} & {$[\mathrm{mm}]$} & \multicolumn{2}{|c|}{ mass fraction } \\
\hline (a) & 3.8 & 0 & 2.85 & 12 & 32 & 0.22 & 0.7452 \\
(b) & 1.785 & 0 & 0 & 12 & 30 & 0.22 & 0.7452 \\
(c) & 0.3 & 0 & 0 & 0.1 & 125 & 0.23 & 0.77
\end{tabular}

For actual simulation, strictly $\mathrm{CH}_{4}, \mathrm{O}_{2}$, and $\mathrm{N}_{2}$ equivalence ratio were varied by keeping other parameters constant for all numerical simulations. The methane-air mixture passes through two separate parts, the perforated plate and the annular axial swirled space.

\subsubsection{Methane-air in the annular swirled space}

The mixture of methane-air passes through an annular space surrounding the axial perforated plate (Fig. 1) which defines the swirler burner valve. Parameters are given in Table II, case a.

$V_{s}$ is obtained by:

$$
V_{s}=V_{\text {ax }} \tan \alpha,
$$

where $\alpha$ is the inclination angle of the swirler vanes valve which is taken as an approximation between the maximum and minimum values in accordance with $[4,13,27]$.

The swirl number $S$ is defined by

$$
S=\frac{2}{3} \tan \alpha\left\{\frac{1-R^{3}}{1-R^{2}+\left[m^{2}\left(1 / R^{2}-1\right)^{2}\right] R^{2}}\right\},
$$

where $R$ is the ratio between the radius of the central duct and the radius of the nozzle burner and $m$ is the rate between the mass flow passing through the central plate and the mass flow passing through the annular swirled space $([4,13])$. 


\subsubsection{Methane-air in the axial perforated plate}

Device section is showed in Fig. 1; it is situated in the axial part of the burner nozzle, where a purely axial velocity of premixed methane-air is posed. Different parameters are posed in Table II, case b.

\subsubsection{The air surrounding the burner nozzle}

The axial velocity of the air was set $20 \mathrm{~mm}$ upstream of the burner nozzle section in Fig. 1. Posed parameters are in Table II, case c.

\subsubsection{Axial output of the computational volume}

This part is supposed further than the nozzle (Fig. 1) where the axial flow is established; $\frac{\partial V}{\partial x_{j}}=0$.

\subsubsection{Tangential output of the computational volume}

The tangential zone bordering the computing domain radially is assumed further than perturbations caused by the flame (Fig. 1), symmetry conditions were posed.

\subsection{Grid refinement}

The mesh is structured no uniform. Figure 2 show the refinement of the mesh grid near the nozzle in close-up view. The area where the refinement is showed coincides with zones of high velocity and temperature gradient to avoid the dependence of the solution to the mesh, several cases were simulated for 83700, 1209000, 1570000 , 1950000 , and 3400000 nodes.

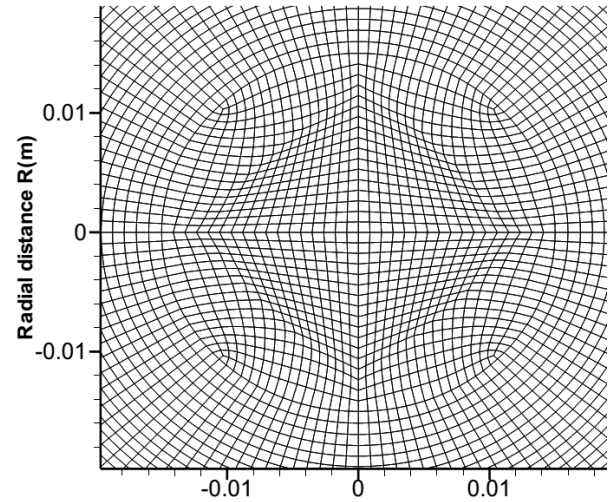

Fig. 2. Close-up of mesh refinement in the centre position.

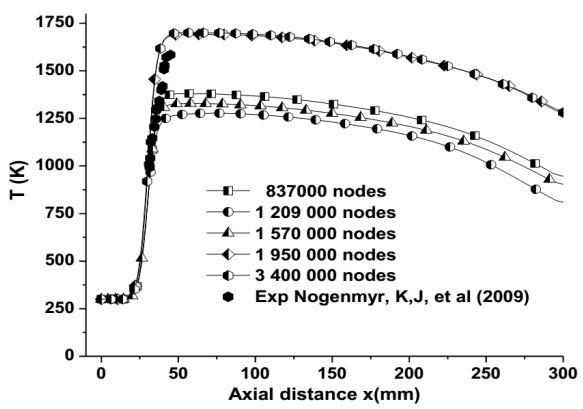

Fig. 3. Temperature profiles along the axis $X$ for different nodes numbers of mesh.

Axial temperature profiles for different number of nodes are showing (Fig. 3) an independence of the solution from 1950000 nodes. The variation of nodes number shows differences of the maximum temperature achieved and its evolution along the axis $X$, however, the position of the flame front from the nozzle burner at $X=0.025 \mathrm{~m}$ was not affected where all mesh cases studied offered a similar solution found by experimental data [13].

\subsection{Validation of axial velocity profiles}

Validation of axial velocity profiles is extremely important for LSB burner. It shows the ability of the used models to predict the velocity field and capture susceptible zones containing vortex which promote the creation of high temperature zones generating significant thermal NO emissions.

Figure 4 shows normalized axial velocities $\left(V_{\mathrm{ax}} / V_{0}\right)$ for actual numerical simulation and [13] experiments and LES data. For sections $X / D=0.2,0.4$, and 0.6, present results are very close to those of LES simulation, but the maximum values are lower than experimental data base.

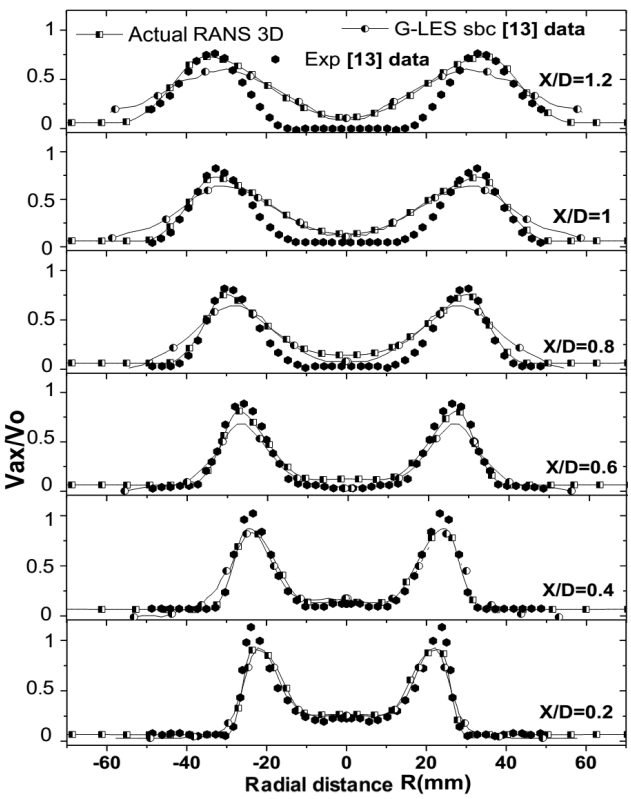

Fig. 4. Axial velocity profiles on different radial sections $(X / D=0.2,0.4,0.6,0.8,1$, and 1.2) and [13] data.

It is noted that for the sections $X / D=0.8,1$, and 1.2 , in the zone between $R=0 \mathrm{~m}$ and $0.02 \mathrm{~m}$, axial velocities provided by actual work are overestimated to the experimental data taken as reference but remains acceptable by comparing them with the LES simulation of the same reference.

\subsection{Validation of temperature profiles}

Velocity profiles along the axial distance $X$ was obtained by adjusting several numerical simulation parameters (Table I). The result is satisfying.

Figure 5 shows great similarities between the present numerical simulation and the results obtained by [13]. The position of the flame front on the axial distance and the maximum of temperature coincide clearly, but its evolution along the axial distance $X$ shows differences between the two numerical simulations. 


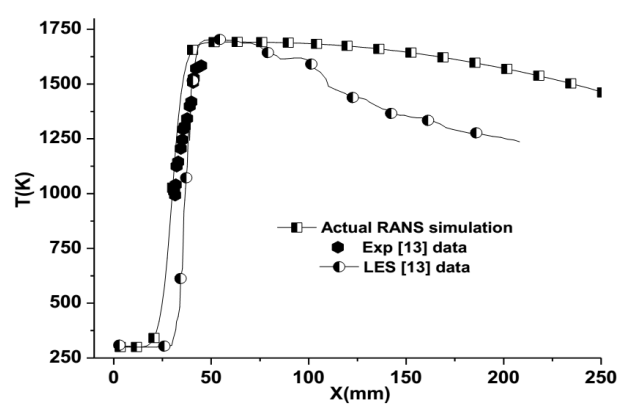

Fig. 5. Temperature profiles along the axial distance $X$ and [13] data.

\subsection{Validation of $\mathrm{CH}_{4}$ distribution profiles}

According to scientific results database, partially premixed combustion model is among the best choices for its ability to predict chemical species fields according to experiences without neglecting turbulence.

Curves shown in Fig. 6 demonstrate the capacity of used models to predict the distribution of $\mathrm{CH}_{4}$, satisfying results were obtained for different sections of the field.

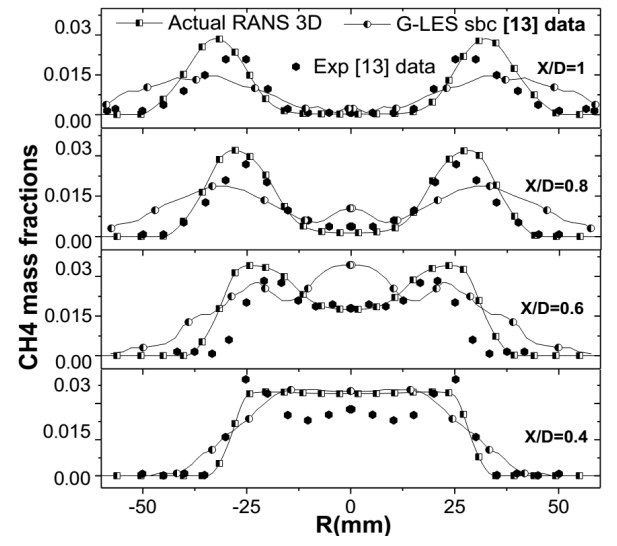

Fig. 6. $\mathrm{CH}_{4}$ mass fraction profiles on different radial sections $(X / D=0.4,0.6,0.8$, and 1$)$ and [13] data.

Overestimation of some studied variable (temperature, velocity and species) is the result of partially premixed combustion model, which considers a fast chemistry neglecting endothermic reaction for combustion ignition process implying an elevation of temperature, a diminution of species density and an elevation of velocity profiles.

A reduced chemical scheme (chemical equilibrium model) with 19 species gave suitable prediction of velocity profiles, temperature profiles and $\mathrm{CH}_{4}$ distribution, this model can be exploited as mentioned by [28], where comparision of reduced and detailed chemical kinetics schemes were made, revealing that a reduced scheme offers acceptable results.

\section{Discussion of results}

$\mathrm{CH}_{4}$ equivalence ratio variation aims to study the applicability limits of LSB in respect of various parameters describing flame structure changes and maximum power that can be achieved without affect flame stability and pollutant creation (thermal NO).

\section{1. $\mathrm{CH}_{4}$ equivalence ratio effects on the temperature field}

The abrupt rise of temperature profiles which is a peculiarity of combustion phenomenon is shown in Fig. 7 . The increase of $\mathrm{CH}_{4}$ equivalence ratio $\Phi$ implies a flame front closest to the nozzle burner. This may cause premature wear o burner and influences the principle of the flame front stabilization and incapacity to maintain a distance from the burner nozzle in LSB burner's kind. Moreover it causes the increase of the temperature (from 1680 to $2200 \mathrm{~K}$ ), but it remains valid in the poor area $(0.6<\Phi<1)$. For the rich field $(1<\Phi<1.4)$ a decrease of the flame temperature is observed, caused by lack of oxygen $\left(\mathrm{O}_{2}\right)$ in the field.

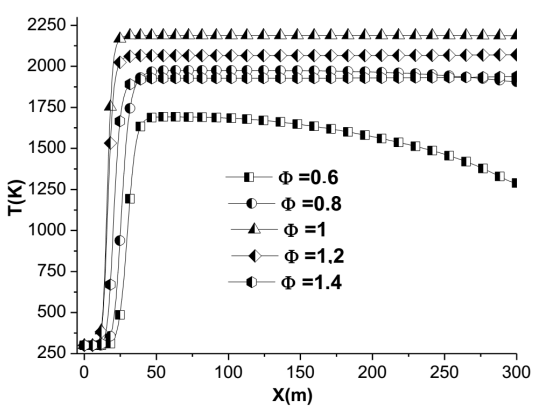

Fig. 7. Temperature profiles along the axis $X$ for different $\mathrm{CH}_{4}$ equivalence ratio.

The increase of $\mathrm{CH}_{4}$ equivalence ratio affects the overall shape of the flame, which comes over larger volume with deformation of the structure from original elliptical shape $(\Phi=0.6)$ to a cylindrical one $(\Phi=1.4)$ as shown in Fig. 8. This new form of the flame front is greater on its edges in the radial distance $R$. It can disrupt its stability, which will be more sensitive to external flow conditions, with increase of the probability of extinction problems and flashbacks. This temperature rise will result in more important appearances of thermal NO pollutants which will be shown in the next curves.

\section{2. $\mathrm{CH}_{4}$ equivalence ratio effects on the velocity flow field}

The dynamic flow field is affected greatly by the combustion that redefines a velocity distribution. As well, $\mathrm{CH}_{4}$ equivalence ratio variation will change the structure of laminar flame speed engendering different dynamic flow fields.

Fig. 9 illustrates, that combustion is shifting maxima of axial velocity to bigger radial distance $R$ comparing with the non-reactive case. Axial velocity value is all over positive, what is confirmed by inexistence of recirculation zones. On section $X / D=0.2$ the axial velocity profiles have not shown differences for different $\mathrm{CH}_{4}$ equivalence ratio. Values are smaller, than for the non-reactive case. 


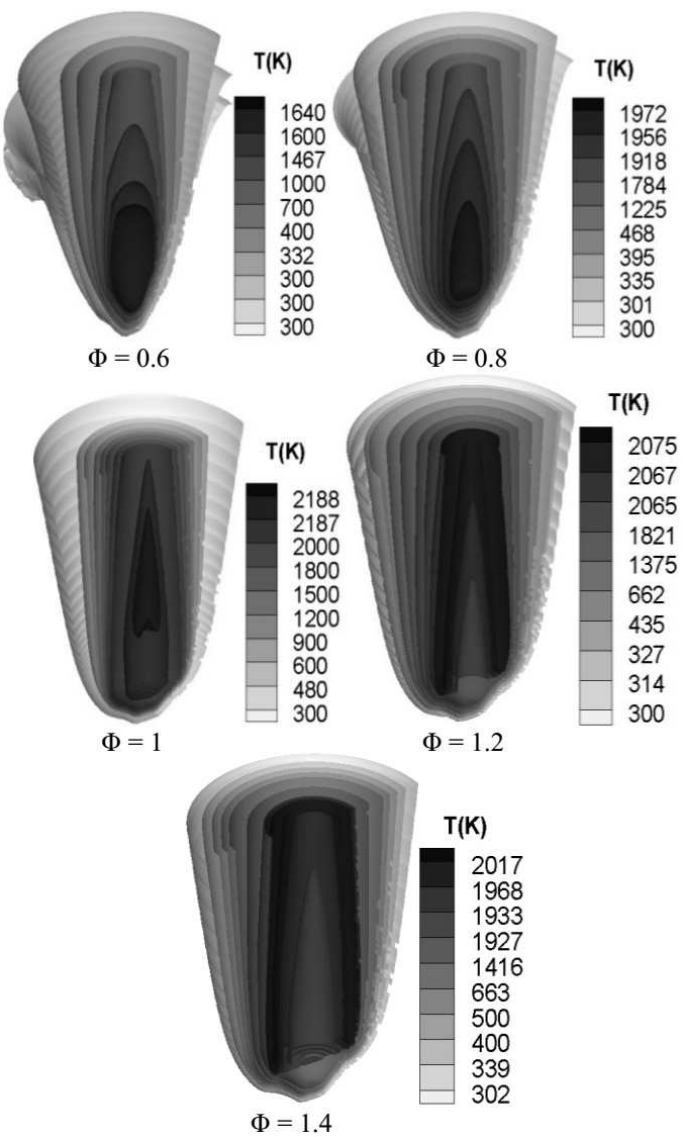

Fig. 8. Temperature iso-surfaces for different $\mathrm{CH}_{4}$ equivalence ratio.

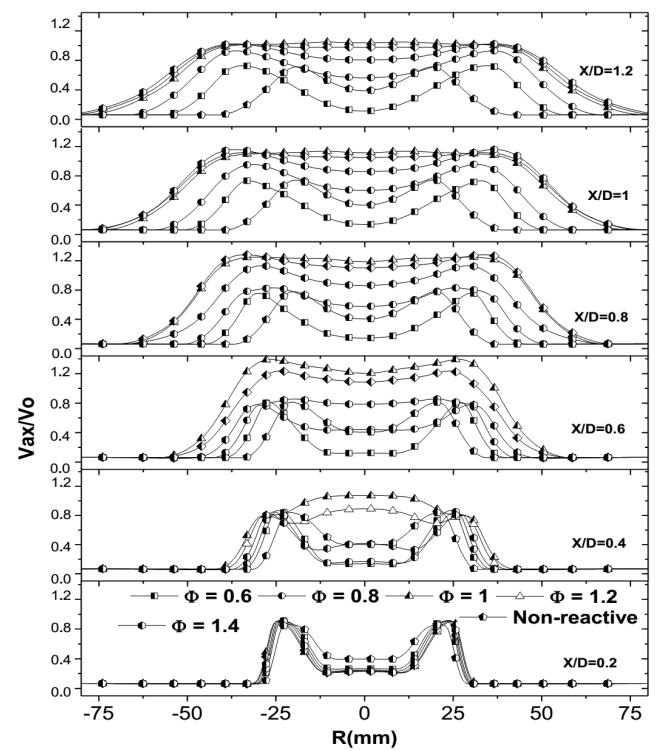

Fig. 9. Axial velocity profiles on different radial sections $(X / D=0.2,0.4,0.6,0.8,1$, and 1.2) for different $\mathrm{CH}_{4}$ equivalence ratio.

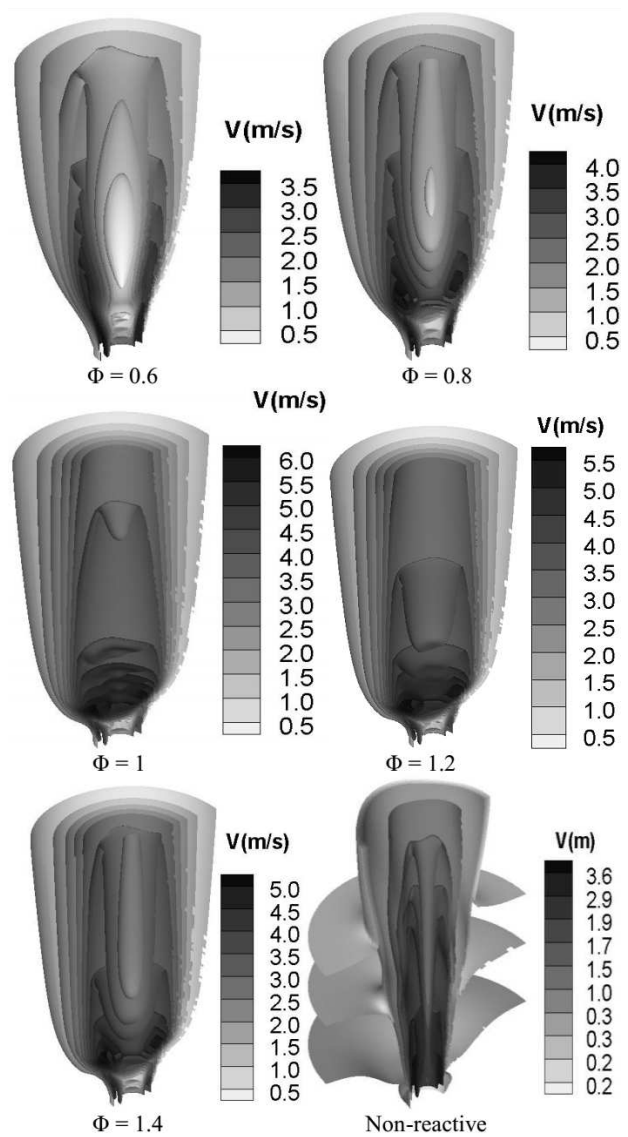

Fig. 10. Axial velocity iso-surfaces for different $\mathrm{CH}_{4}$ equivalence ratio.

It could be explained by the stabilization of the flame, when the combustion reaction begins.

The axial velocity values increase proportionally with $\mathrm{CH}_{4}$ equivalence ratio for the $\Phi=0.6,0.8$, and 1 cases. The maximum axial velocity is reached for $\Phi=1$ case, which allows to deduce that the axial velocities depend strongly on the temperature field.

For $\Phi=1.2$ and 1.4 cases, axial velocity profiles are less significant compared to the stoichiometric case, which is the result of the temperature decrease and the appearance of a broader area of flame. These results showed that the poor case $(\Phi=0.6)$ develops an axial velocity field which resembles the non-reactive case, which allows better stabilization of the flame.

The increasing of $\mathrm{CH}_{4}$ equivalence ratio does not show apparitions of recirculation zones which provide stabilization of the flame (Fig. 10). Nevertheless, its augmentation does increase the values of axial velocities that redefine a wider flow field stressing that the case $\Phi=0.6$ offers a similar flow field to the non-reactive case. This leaves us to say that increased $\mathrm{CH}_{4}$ equivalence ratio may cause flame instability.

4.3. $\mathrm{CH}_{4}$ equivalence ratio effects on $\mathrm{CH}_{4}$ distribution

$\mathrm{CH}_{4}$ equivalence ratio variations will redefine a new field of chemical species distribution related to the new flame structure and laminar flame speed. 
Figure 11 shows the increase of $\mathrm{CH}_{4}$ equivalence ratio in the reactive mixture. Changes in $\mathrm{CH}_{4}$ mass fraction distribution in the field is due to the difference of the dynamic and thermal fields. On section $X / D=0.2$, the values of $\mathrm{CH}_{4}$ mass fraction reflect the boundary conditions posed and the flame was not developed yet. However, for the remaining sections, the distribution depends on the location of the reaction zones defined by the dynamic field.

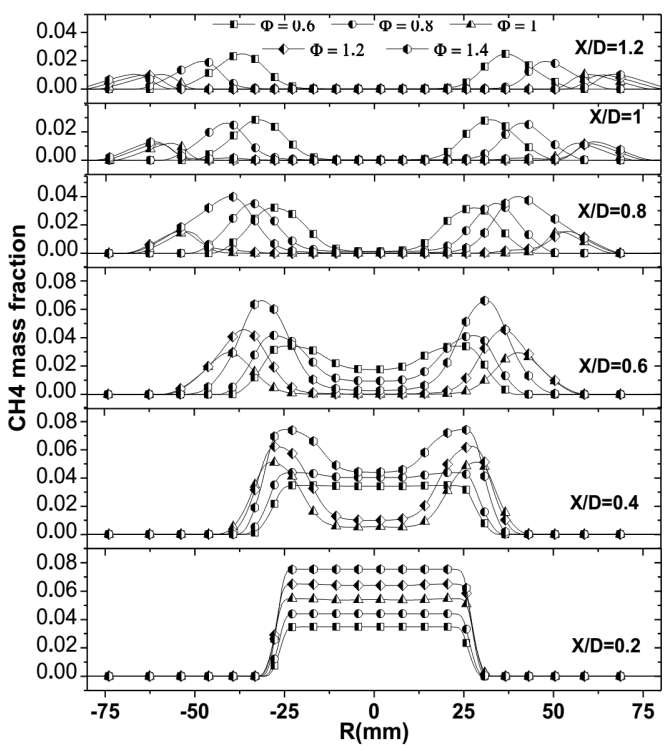

Fig. 11. $\mathrm{CH}_{4}$ mass fraction profiles on different radial sections $(X / D=0.2,0.4,0.6,0.8,1$, and 1.2$)$ for different $\mathrm{CH}_{4}$ equivalence ratio.

For sections $X / D=0.4$ and $0.6, \mathrm{CH}_{4}$ mass fraction is most important on the axial zone $(-0.025 \mathrm{~m}<R<$ $0.025 \mathrm{~m}$ ) for $\Phi=0.6$ case, this is due to flame blowing relative to the burner nozzle. We deduce that for low $\mathrm{CH}_{4}$ equivalence ratio, the flame is farther from the burner nozzle.

On the same section $(X / D=0.6)$ and $X / D=0.8$, in the case of $\Phi=1.4$, we find that the $\mathrm{CH}_{4}$ mass fraction is the most important in the field then the methane remains not burned.

4.4. $\mathrm{CH}_{4}$ equivalence ratio effects on $\mathrm{NO}$ apparition

Creation of thermal NO is significant part of this study. Thermal NO model [22-24] gave an analyze of thermal NO creation. The maximum of NO creation is noted on the axial distance $X$ of the burner and various sections of the domain who reflect areas of high temperature.

Fig. 12 shows, that the increase of $\mathrm{CH}_{4}$ mass fraction creates a greater quantity of thermal NO, due to temperature increase. The methane-air composition does not directly affect its creation. This could be explained as the result of existence of high temperature zones, followed by the decrease of the onset of thermal NO case for $\Phi=1.2$ and 1.4.

The thermal NO mass fraction depends mainly on developing a high temperature zones (Fig. 13), but it is not

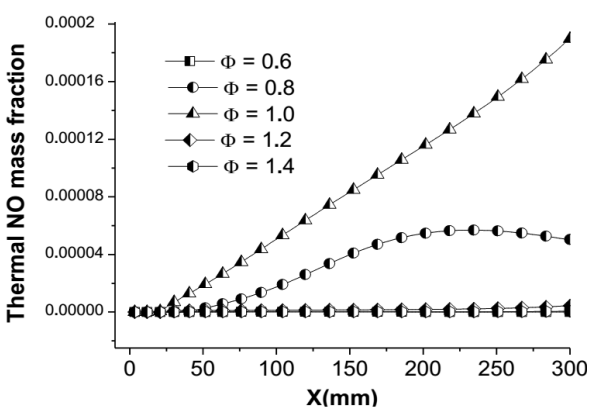

Fig. 12. Thermal NO mass fraction profiles on the axial distance $X$ for different $\mathrm{CH}_{4}$ equivalence ratio.

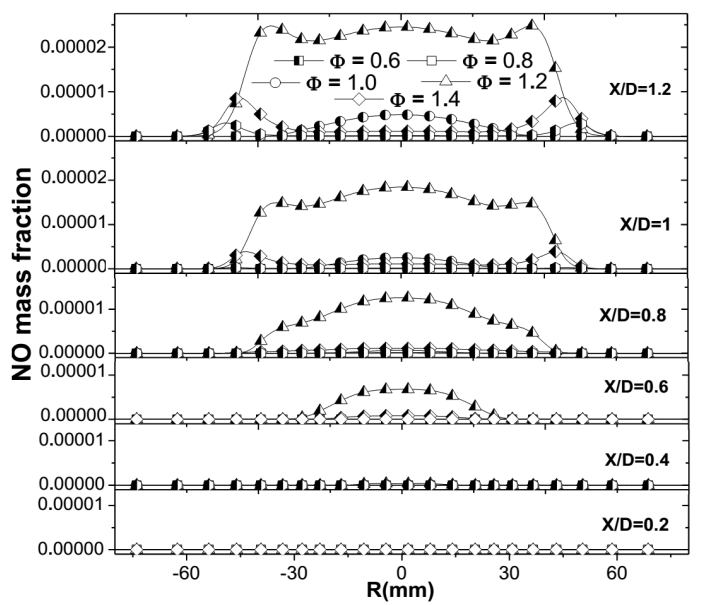

Fig. 13. NO mass fraction profiles on different radial sections $(X / D=0.2,0.4,0.6,0.8,1$, and 1.2$)$ for different $\mathrm{CH}_{4}$ equivalence ratio.

linked intrinsically with increase of $\mathrm{CH}_{4}$ equivalence ratio. On sections $X / D=0.2$ and 0.4 , we note the absence of pollutants $\mathrm{NO}$ for all values of $\mathrm{CH}_{4}$ equivalence ratio, that could be explained by synthesis of NO in areas of high temperature, inexistant in this case. For other sections $(X / D=0.6,0.8,1$, and 1.2), the stoichiometric case $\Phi=1$ ) brings up the maximum of NO pollutants because it is the latter that develops areas with high temperature. The appearance of NO pollutants is not due to the presence of recirculation zones or turbulence instabilities favoring an increase of temperature, their appearances are related to highly exothermic combustion zones for the stoichiometric case neighboring $\mathrm{CH}_{4}$ equivalence ratio of $\Phi=1$.

At lean conditions, thermal NO apparitions are related to heat release instabilities. But at a weak swirl number, the turbulence induce low frequency fluctuations which cause gross flame brush bouncing and velocity profiles are not very different than the non-reacting case [4], weak $\mathrm{CH}_{4}$ equivalence ratio may cause heat release instabilities (near the extinction domain) but the stabilization process (with low swirl number) remedied this. 


\section{Conclusion}

A numerical simulation study of premixed methane-air flame with low swirl number using RANS and partially premixed model has been developed and validated.

The models are applicable to wide range of $\mathrm{CH}_{4}$ equivalence ratio of fuel-air mixture.

Obtained results of the numerical simulation were acceptable and proved that the flame is strictly detached from the nozzle, thus demonstrating the operating principle of this kind of burners (LSB).

Partially premixed combustion model has proven its ability to predict and analyze the distribution of chemical species $\left(\mathrm{CH}_{4}\right.$ and air) and the creation of pollutants (thermal NO).

The turbulence model using RANS $\kappa-\varepsilon$ standard is able to predict a flow field of flame describing its structure. This can be a significant advance in the field of numerical simulation applied in this domain. Required time and computing resources are less important than those required by the LES and direct numerical simulation turbulence models, especially for large structures of LSB burners.

The increasing equivalence ratio of $\mathrm{CH}_{4}$ does not affect in a direct way the appearance of thermal NO. However, it showed that the flame front is most significant in the radial boundaries where the temperature was most important. Therefore, the flow field may become more sensitive to external flow conditions and consequently increase the risk of dynamic instability and extinction. On the other hand, its augmentation does not form recirculation zones, which shows, that LSB is very good solution for the zero emissions concepts.

The burner exploited in this study was designed for a capacity of $27 \mathrm{~kW}$. We do not recommend the increase of $\mathrm{CH}_{4}$ equivalence ratio in the fuel to achieve higher power. Redimensioning of the global structure of burner could be more wisely.

\section{References}

[1] K. Truffin, Ph.D. thesis, Institut National Polytechnique de Toulouse, 2005.

[2] D. Veynante, L. Vervisch, Prog. Energy Comb. Sci. 28, 266 (2002).

[3] Y. Huang, Y. Vigor, Prog. Energy Comb. Sci. 35, 293 (2009).

[4] R.K. Cheng, Comb. Flame 101, 1 (1995).

[5] T. Plessing, C. Kortschik, N. Peters, M.S. Mansour, R.K. Cheng, Proc. Comb. Inst. 28, 359 (2000).
[6] J.B. Bell, M.S. Day, J.F. Grcar, Proc. Comb. Inst. 29, 1987 (2002).

[7] M.R. Johnson, D. Littlejohn, W.A. Nazeer, K.O. Smith, R.K. Cheng, Proc. Comb. Inst. 30, 2867 (2005).

[8] Y. Huang, V. Yang, Proc. Comb. Inst. 30, 1775 (2005).

[9] T.S. Cheng, C.Y. Wu, Y.H. Li, Y.C. Chao, Combust. Sci. Tech. 178, 1821 (2006).

[10] J.B. Bell, R.K. Cheng, M.S. Day, I.G. Shepherd, Proc. Comb. Inst. 31, 1309 (2007).

[11] S. Pfadler, A. Leipertz, F. Dinkelacker, J. Wäsle, A. Winkler, T. Sattelmayer, Proc. Comb. Inst. 31, 1337 (2007)

[12] J. Galpin, A. Naudin, L. Vervisch, C. Angelberger, O. Colin, P. Domingo, Comb. Flame 155, 247 (2008).

[13] K.J. Nogenmyr, C. Fureby, X.S. Bai, P. Petersson, R. Collin, M. Linne, Comb. Flame 156, 25 (2009).

[14] D. Littlejohn, R.K. Cheng, D.R. Noble, L. Tim, J Eng. Gas Turbines Power 132, 011502-1 (2010).

[15] P. Petersson, R. Wellander, J. Olofsson, H. Carlsson, C. Carlsson, B.B. Watz, N. Boetkjaer, M. Richter, M. Aldén, L. Fuchs, X.S. Bai, in: Proc. 16th Int. Symp. Appl. Laser Techn. Fluid Mech., Lisbon 2012.

[16] Fluent 14, Guide theory, 2010.

[17] B.E. Launder, D.B. Spalding, Lectures in Mathematical Models of Turbulence, Academic Press, London 1972.

[18] V. Zimont, Exp. Thermal Fluid Sci. 21, 179 (2000).

[19] V. Zimont, W. Polifke, M. Bettelini, W. Weisenstein, J. Gas Turbines Power 120, 526 (1998).

[20] V.L. Zimont, A.N. Lipatnikov, Chem. Phys. Report 14, 993 (1995).

[21] S.B. Pope, Prog. Energy Comb. Sci. 11, 119 (1985).

[22] W.L. Flower, R.K. Hanson, C.H. Kruger, in: 15th Int. Symp. Combustion, Combustion Institute, Pittsburgh 1975, p. 823.

[23] J. Blauvens, B. Smets, J. Peters, in Ref. [15].

[24] J.P. Monat, R.K. Hanson, C. H. Kruger, in: 17th Int. Symp. Combustion, Combustion Institute, Pittsburgh 1979, p. 543.

[25] A.J. Chorin, Math. Comp. 22, 745 (1968).

[26] J.P. Vandoormaal, G.D. Raithby, Numer. Heat Transfer 7, 147 (1984).

[27] B. Pesenti, Ph.D. thesis, Faculté Polytechnique de MONS, Service de Thermique et Combustion, 2006.

[28] A. Guessab, A. Aris, I. Gökalp, F. Tabet Helat, J. Phys. Sci. Appl. 36, 400 (2013). 